\title{
Variable diffusion boundary layer and diffusion flux at sediment- water interface in response to dynamic forcing over an intertidal mudflat
}

\author{
WANG JiaNing ${ }^{1}$, ZHAO Liang ${ }^{1} \&$ WEI Hao ${ }^{2 *}$ \\ ${ }^{1}$ Laboratory of Physical Oceanography, College of Physical and Environmental Oceanography, Ocean University of China, Qingdao 266100, \\ China; \\ ${ }^{2}$ College of Marine Science and Engineering, Tianjin University of Science and Technology, Tianjin 300457, China
}

Received November 18, 2011; accepted January 6, 2012; published online February 21, 2012

\begin{abstract}
The diffusion boundary layer (DBL) significantly limits the exchange between sediment and overlying water and therefore becomes a bottleneck of diffusive vertical flux at the sediment-water interface (SWI). Variable DBL thickness and diffusion flux in response to dynamic forcing may influence replenishment of nutrients and secondary pollution in coastal waters. In situ measurements of velocity in the bottom boundary layer (BBL) and oxygen concentration in the DBL were made over an intertidal mudflat, using an acoustic Doppler current and mini profiler. A linear distributed zone in the oxygen profile, the profile slope discontinuity and variance of concentration can be used to derive accurate DBL thickness. Diffusion fluxes calculated from the water column and sediment are identical, and their bias is less than 6\%. A numerical model PROFILE is used to simulate the in situ dissolved oxygen profile, and layered dissolved oxygen consumption rates in the sediment are calculated. The DBL thickness $(0.10-0.35$ $\mathrm{mm})$ and diffusion flux (15.4-53.6 mmol m $\mathrm{m}^{-2} \mathrm{~d}^{-1}$ ) vary with a factor of 3.5 during a tidal period. Over an intertidal mudflat, DBL thickness is controlled by flow speed $U$ in the BBL, according to $\delta_{\mathrm{DBL}}=1686.1 D U^{-1}+0.1$ ( $D$ is the molecular diffusion coefficient). That is, the DBL thickness $\delta_{\mathrm{DBL}}$ increases with decreasing flow speed $U$. Changes of diffusion flux at the SWI are caused by variations in the water above the sediment and the turbulent mixing intensity. The diffusion flux is positively related to the turbulent dissipation rate, friction velocity and turbulent energy. Under the influence of dynamics in the BBL, DBL thickness and flux vary significantly.
\end{abstract}

diffusion boundary layer, diffusion flux, dynamic forcing, mini profiler, dissolved oxygen, intertidal mudflat

Citation: Wang J N, Zhao L, Wei H. Variable diffusion boundary layer and diffusion flux at sediment-water interface in response to dynamic forcing over an intertidal mudflat. Chin Sci Bull, 2012, 57: 1568-1577, doi: 10.1007/s11434-012-4988-3

The diffusion boundary layer (DBL) is a thin (less than 1 $\mathrm{mm}$ ) film of water covering the sediment. When solutes and particles are transported from the bottom boundary layer (BBL) to the DBL, molecular diffusion instead of turbulent eddy diffusion dominates the vertical transport [1-3]. The DBL limits exchange between the sediment and overlying water, and therefore becomes a bottleneck of diffusive vertical flux at the sediment-water interface (SWI). Higashino et al. [4-6] theoretically revealed that dynamic forcing in the BBL has a direct effect on DBL thickness and diffusion

\footnotetext{
*Corresponding author (email: weihao@ouc.edu.cn)
}

flux at the SWI. Under the influence of dynamics in the BBL, DBL thickness and flux vary significantly. Understanding how the DBL and diffusion transport responds to dynamic forcing is therefore crucial for accurately quantifying diffusion flux, and for estimating the replenishment of nutrients and secondary pollution in coastal waters. Modeling also requires numerical parameterization of diffusion flux as a function of BBL dynamics. The diffusive vertical flux of dissolved oxygen at the SWI affects benthic and overall water quality of natural aquatic systems. Therefore, dissolved oxygen is chosen as the studied solute $[7,8]$.

Using dimensional analysis of the Reynolds equation, the 
boundary layer with constant total shear stress near the wall can be divided into viscous (i.e. DBL) and logarithmic layers (i.e. BBL), which are controlled by molecular friction and turbulent friction, respectively [9]. Jørgensen and Revsbech [1] first conducted measurements in the DBL using a dissolved oxygen probe in the laboratory, and reported that DBL thickness varied from 0.2 to $>1 \mathrm{~mm}$, depending on water velocity and roughness of the solid surface. Subsequent comprehensive laboratory measurements revealed that small-scale topography had an impact on the distribution of the DBL $[10,11]$; DBL thickness significantly decreased with increasing flow velocity [12-14]; and there was a linear relation between the mass transfer coefficient $\beta$ and turbulent friction velocity $u^{*}[13,14]$. Most previous studies were based on laboratory experiments. Other studies were done under natural conditions in the field, where the DBL was deduced by fitting the profile of some solute in $1 \mathrm{~mm}$. The DBL was first investigated by Reimers et al. [15] in the sea, using an oxygen probe at vertical increments of $1 \mathrm{~mm}$; this resolution is now regarded as inadequate. The vertical resolution of DBL measurement improved from 0.5 [16] to $0.05 \mathrm{~mm} \mathrm{[2]} \mathrm{as} \mathrm{technology} \mathrm{evolved.}$ Guld et al. [17] did field observation and documented temporal and spatial variation of the DBL and flux. While most of the above studies emphasized the importance of hydrodynamics to DBL thickness, little work has been done to quantify the relation between dynamic forcing in the BBL and DBL thickness. Lorke et al. [18] and Bryant et al. [8] conducted in situ investigation of BBL dynamics with simultaneous DBL in a lake, and discussed their relation. However, lakes are less energetic than oceans. To the authors' knowledge, no combined observation has been done in seas.

Taking advantage of an observation platform of the BBL and a Mini Profiler MP4 with oxygen probe, we made simultaneous field measurements of BBL dynamics in conjunction with the DBL over an intertidal mudflat. We use the resulting data to analyze DBL thickness, flux at the SWI, dynamic factors (e.g. flow speed and turbulence) and their relationships.

\section{Implementation of in situ measurement}

Field measurements were made for one tidal period over an intertidal mudflat of Huichang Bay in Qingdao (Figure 1), where the semidiurnal tidal current was dominant. Intertidal mudflats are influenced by the rise and fall of tides, and the sediment is covered by seawater for about half of the tidal period. The measurement period was from 17:20 to 22:40 local time on 27 November, 2010. A 6 MHz Nortek "Vector" acoustic Doppler current meter (ADV) and a XR-620 RBR (for Conductivity, Temperature, Depth or CTD) were mounted on a tripod frame on the seabed. A Mini Profiler MP4 with its own tripod frame was installed nearby, to ensure the same dynamic forcing and sediment type.

\subsection{Measurement of oxygen profile using mini profiler}

The Mini Profiler MP4 is usually packed with a Clark-type oxygen probe (OX25, Unisense S/A, Denmark) and a micro-step controlled motor (Figure 2). The outside tip diameter of the probe is $25 \mu \mathrm{m}$, and $90 \%$ of response times are less than $4 \mathrm{~s}$. The greatest vertical spatial resolution of the motor is $50 \mu \mathrm{m}$. These parameters assure the study of DBL microstructure $\left(\delta_{\mathrm{DBL}} \leqslant 1 \mathrm{~mm}\right)$.

Oxygen profile measurements were conducted every $\sim 30$ min, lasting 25-30 min. The spatial resolution of the profile

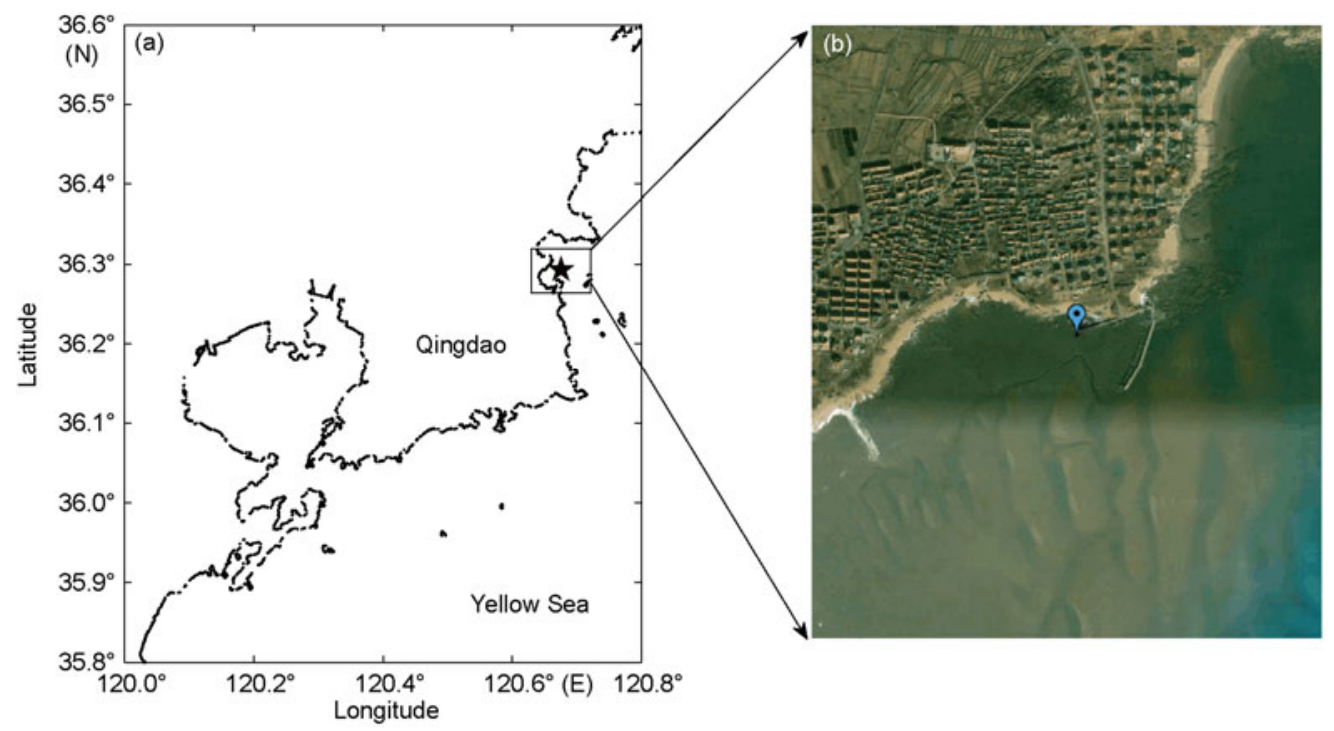

Figure 1 Map of study site. Mooring station, marked by solid star (a) and dotted blue marker (b), was over an intertidal mudflat of Huichang Bay in Qingdao ((a) was adapted from Google Earth). 


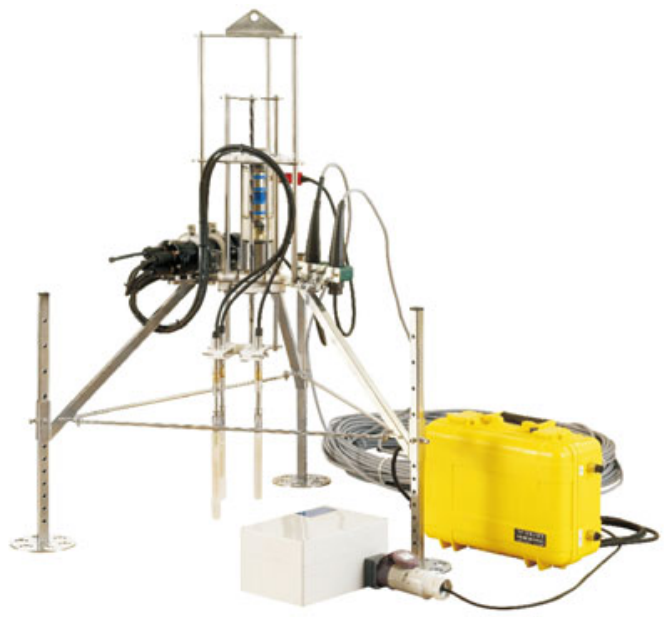

Figure 2 Schematic of Mini Profiler MP4 (http://www.unisense.com/ Default.aspx?ID=97).

was $50 \mu \mathrm{m}$, and oxygen concentrations were collected five times at each depth. Measurement began at 1-2 $\mathrm{mm}$ above the sediment, and was terminated when the oxygen concentration signal decreased to low values over a long duration. Therefore, the profiles contained the low boundary of the BBL, the DBL, all sediment oxic zone, and the upper boundary of the sediment anoxic zone (Figure 3).

\subsection{Measurement of dynamic forcing in BBL}

The "downward-looking" ADV at 0.22 mab was set up to work in burst mode. The interval between two bursts of measurement is $4 \mathrm{~min}$. Every burst lasts $6 \mathrm{~min}$, with data being collected at a rate of $8 \mathrm{~Hz}$. Liu and Wei [19] detailed techniques for using ADV data to calculate the mean velocity, applying the inertial dissipation method to estimate the turbulent energy dissipation rate, and using the eddy correlation method to estimate friction velocity. The energy per unit mass carried by velocity fluctuations is called turbulent kinetic energy, which can be obtained from $K=\left(\left(u^{\prime}\right)^{2}+\left(v^{\prime}\right)^{2}\right.$ $\left.+\left(w^{\prime}\right)^{2}\right) / 2$, where $u^{\prime}, v^{\prime}$ and $w^{\prime}$ are eastward, northward and vertical velocity perturbations, respectively. Using the aforementioned methods, we obtained mean velocity, turbulent energy dissipation rate, friction velocity and turbulent kinetic energy. The CTD measurement at height 0.40 mab was set up to work continuously with sample frequency $1 \mathrm{~Hz}$, to measure temperature and salinity in the BBL. This provided the basis for calculating molecular diffusivity.

\section{Data processing and model reproduction}

\subsection{DBL thickness}

The transport of solutes is controlled by vertical molecular diffusion in the DBL. Assuming there is no extra oxygen consumption and production, the vertical concentration of oxygen $(\partial C / \partial z)$ should be constant and oxygen concentration in the DBL should decrease linearly toward the SWI [14]. Therefore, the linear distributed zone in the oxygen profile (Figure 3 ) is one way to assess DBL thickness.

To satisfy conservation of mass, the flux calculated on the water side and sediment side of the SWI must be equal. This constraint, combined with a smaller diffusivity in sediment than water, forces the gradient of oxygen concentration to be steeper here, forming a slope discontinuity in the profile at the SWI [20]. This slope discontinuity can be used to define DBL thickness (Figure 3).

Lorke et al. [18] proposed that the concentration variance decreases drastically because of diminishing eddy diffusion when the oxygen sensor approaches the sediment surface, and remains a minimum in the pore water [2]. Therefore, the SWI should be where the concentration variance decreases substantially (Figure 3).

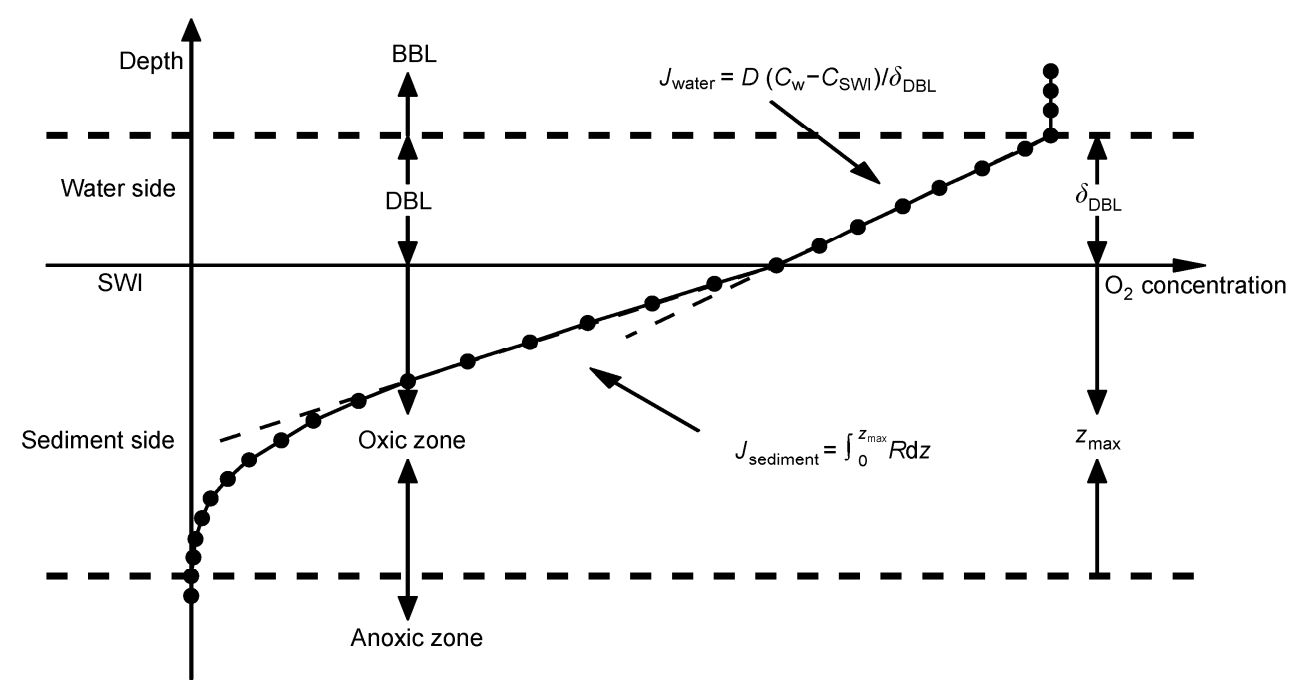

Figure 3 Theoretical distribution of oxygen concentration in the BBL, DBL and sediment. 
To accurately estimate DBL thickness, the three methods above, i.e., the linear distributed zone in the oxygen profile, slope discontinuity of the profile and concentration variance, were used integrally.

\subsection{Diffusion flux at SWI}

The diffusion flux of dissolved oxygen may also be called vertical $\mathrm{O}_{2}$ diffusion uptake by the sediment. Variations of terrain, convection of pore water and irrigation effects are ignored here. The flux can be calculated from the water column side and from the sediment side (Figure 3). The oxygen uptake is frequently evaluated from the water column side, based on Fick's first law of diffusion:

$$
J_{\text {water }}=D \frac{C_{\mathrm{w}}-C_{\mathrm{SWI}}}{\delta_{\mathrm{DBL}}},
$$

where $C_{\mathrm{w}}$ is oxygen concentration in the bottom water, $C_{\mathrm{SWI}}$ is oxygen concentration at the SWI, $\delta_{\mathrm{DBL}}$ is DBL thickness, and $D$ is the molecular diffusion coefficient for oxygen in water, which is only affected by temperature and salinity.

Oxygen uptake can also be evaluated from the sediment side, through vertically integrating the oxygen consumption rate from the SWI to $z_{\max }$ :

$$
J_{\text {sediment }}=\int_{0}^{z_{\max }} R \mathrm{~d} z
$$

where $R$ is the net rate of oxygen consumption per unit volume of sediment, and $z_{\max }$ is the depth of the sediment oxic zone (Figure 3 ).

The two methods both ignore the temporal change of oxygen $(\partial C / \partial t=0)$. Evaluating the flux of oxygen from the water side is the most direct approach, but there are several problems associated with quantifying DBL thickness. These problems can be avoided by using the sediment side method, but it is often more sensitive to relatively complex sediment processes.

\subsection{Numerical model PROFILE}

The numerical model PROFILE proposed by Berg et al. [21] was used to stimulate the in situ dissolved oxygen profile. Applying the model rather than linking measured data directly can distinguish abnormal data produced by bubbles and biologic activity, so model results show the profile structure accurately. The sediment porosity parameter is adjusted with PROFILE via a trial-and-error method. PROFILE defines multiple zones of constant consumption to best describe the oxygen profile through $F$ statistics. Further, the layered dissolved oxygen consumption rate in the sediment is calculated.

Assuming steady-state conditions, the one-dimensional mass conservation equation of PROFILE that accounts for the effects of molecular diffusion, bioturbation, and irrigation (pumping activity of animals) is

$$
\frac{\mathrm{d}}{\mathrm{d} x}\left(\varphi\left(D_{\mathrm{s}}+D_{\mathrm{B}}\right) \frac{\mathrm{d} C_{\mathrm{s}}}{\mathrm{d} x}\right)+\alpha\left(C_{\mathrm{w}}-C_{\mathrm{s}}\right)+R=0,
$$

where $x$ is depth, $C_{\mathrm{s}}$ is pore water concentration, $C_{\mathrm{w}}$ is bottom water concentration, $\varphi$ is porosity, $D_{\mathrm{s}}$ is the molecular diffusivity corrected for tortuosity, $D_{\mathrm{B}}$ is biodiffusivity, $\alpha$ is the irrigation coefficient, and $R$ is the net rate of production (or consumption, if $R$ is negative) per unit volume of sediment.

To be consistent with the aforementioned diffusion flux, irrigation and bioturbation effects were assumed negligible, i.e. $\alpha=0$ and $D_{\mathrm{B}}=0$. The model's upper boundary is set at the top of the DBL, where the concentration of dissolved oxygen is given by measurement; lower boundary is set at the lowest point of oxic zone, where the oxygen flux is taken as zero.

\section{Data analysis}

\subsection{DBL thickness and diffusion flux into the sediment}

The 11 measured dissolved oxygen profiles are shown in Figure 4. The square of correlation coefficients $\left(R^{2}\right)$ between model results and observations all exceed 0.99 , which indicates that the model describes the distribution of oxygen in the DBL and sediment well. The high $R^{2}$ values of 0.99 further indicate that the model assumption of steady state is nearly satisfied, and vertical transport is mainly controlled by molecular diffusion. Figure 4 shows that the dissolved oxygen profile in the DBL is linearly distributed and its thickness, which is between 0.10 and $0.35 \mathrm{~mm}$, varies with a factor of 3.5 over one tidal period. The average DBL thickness of $0.25 \mathrm{~mm}$ reveals that it is a very thin layer above the SWI. The temperature and salinity measured by RBR CTD define the oxygen molecular diffusion coefficient $D$ [22], which varies between $1.47 \times 10^{-5}$ and $1.51 \times 10^{-5}$ $\mathrm{cm}^{2} \mathrm{~s}^{-1}$. The diffusion fluxes calculated from the water column $J_{\text {water }}$ and from the sediment $J_{\text {sediment }}$ remain the same, and their bias $\left(\left(J_{\text {water }}-J_{\text {sediment }}\right) / J_{\text {water }} \times 100 \%\right)$ is less than $6 \%$. Thus, using results from the two methods, mean values of $J_{\text {water }}$ and $J_{\text {sediment }}$ are calculated for each oxygen profile. The dissolved oxygen diffusion flux into sediment varies from 15.4 to $53.6 \mathrm{mmol} \mathrm{m} \mathrm{d}^{-1}$, with an average of $25.4 \mathrm{mmol}$ $\mathrm{m}^{-2} \mathrm{~d}^{-1}$. As with DBL thickness, the diffusion flux also changes with a factor of 3.5 over one tidal period.

Figure 4 also shows that the net rate of consumption per unit volume of sediment increases when the diffusion flux intensifies. The diffusion flux of profile $1(17: 19)$ is 53.6 mmol m $\mathrm{m}^{-2} \mathrm{~d}^{-1}$, at the same time the maximum net rate of oxygen consumption reaches $1.7 \mathrm{nmol} \mathrm{cm} \mathrm{cm}^{-3}$. However, the diffusion flux of profile 11 (22:30) is only $15.4 \mathrm{mmol}$ $\mathrm{m}^{-2} \mathrm{~d}^{-1}$, contemporaneous with a decline in the maximum 

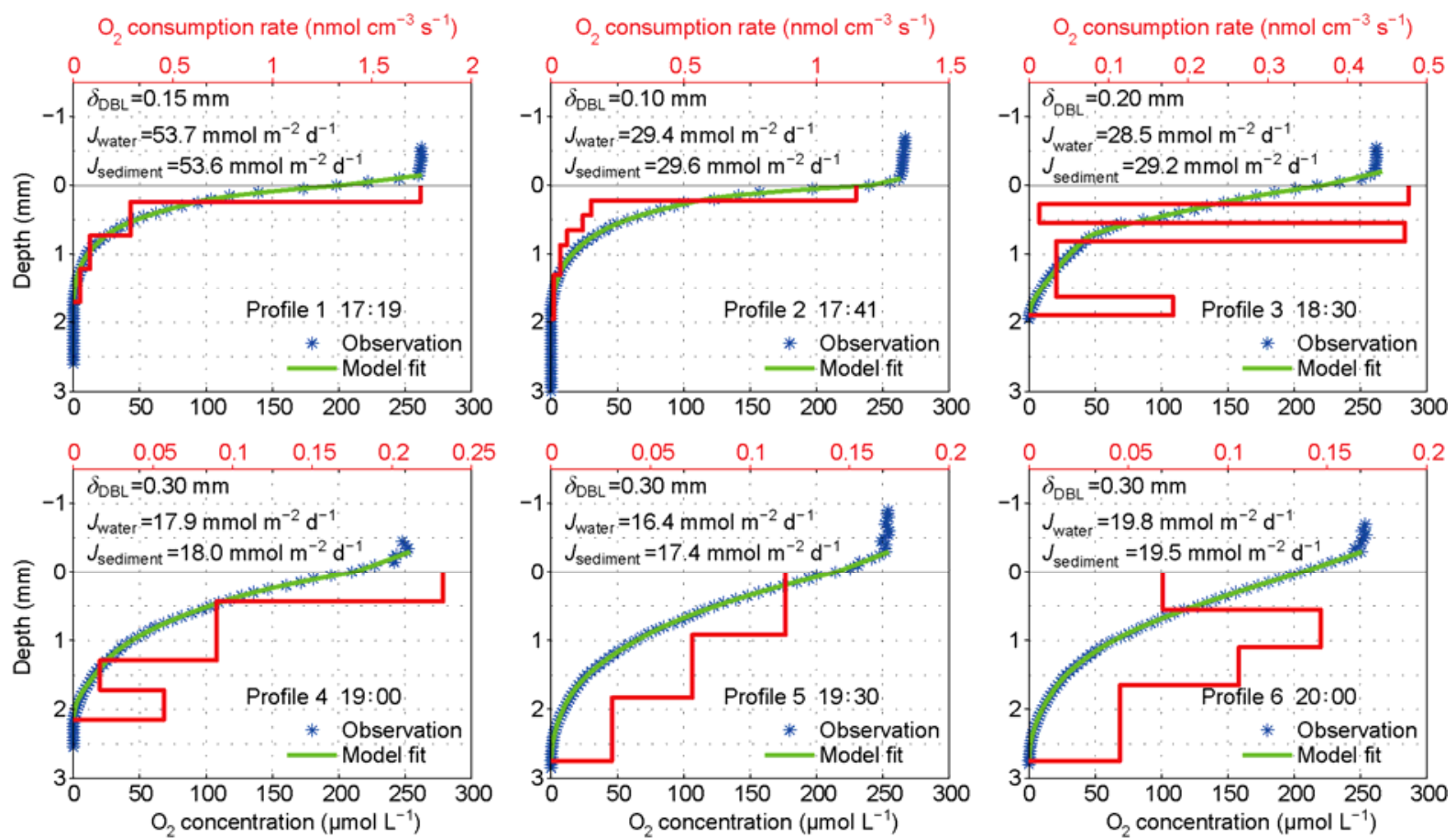

$\mathrm{O}_{2}$ consumption rate $\left(\mathrm{nmol} \mathrm{cm} \mathrm{cm}^{-3} \mathrm{~s}^{-1}\right.$ )

$\mathrm{O}_{2}$ consumption rate $\left(\mathrm{nmol} \mathrm{cm} \mathrm{cm}^{-3} \mathrm{~s}^{-1}\right.$ )
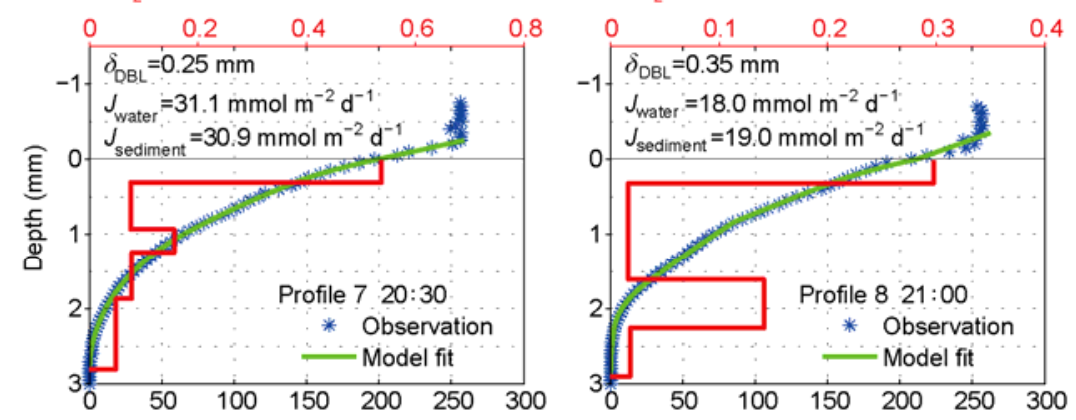

$\mathrm{O}_{2}$ consumption rate $\left(\mathrm{nmol} \mathrm{cm} \mathrm{cm}^{-3} \mathrm{~s}^{-1}\right)$
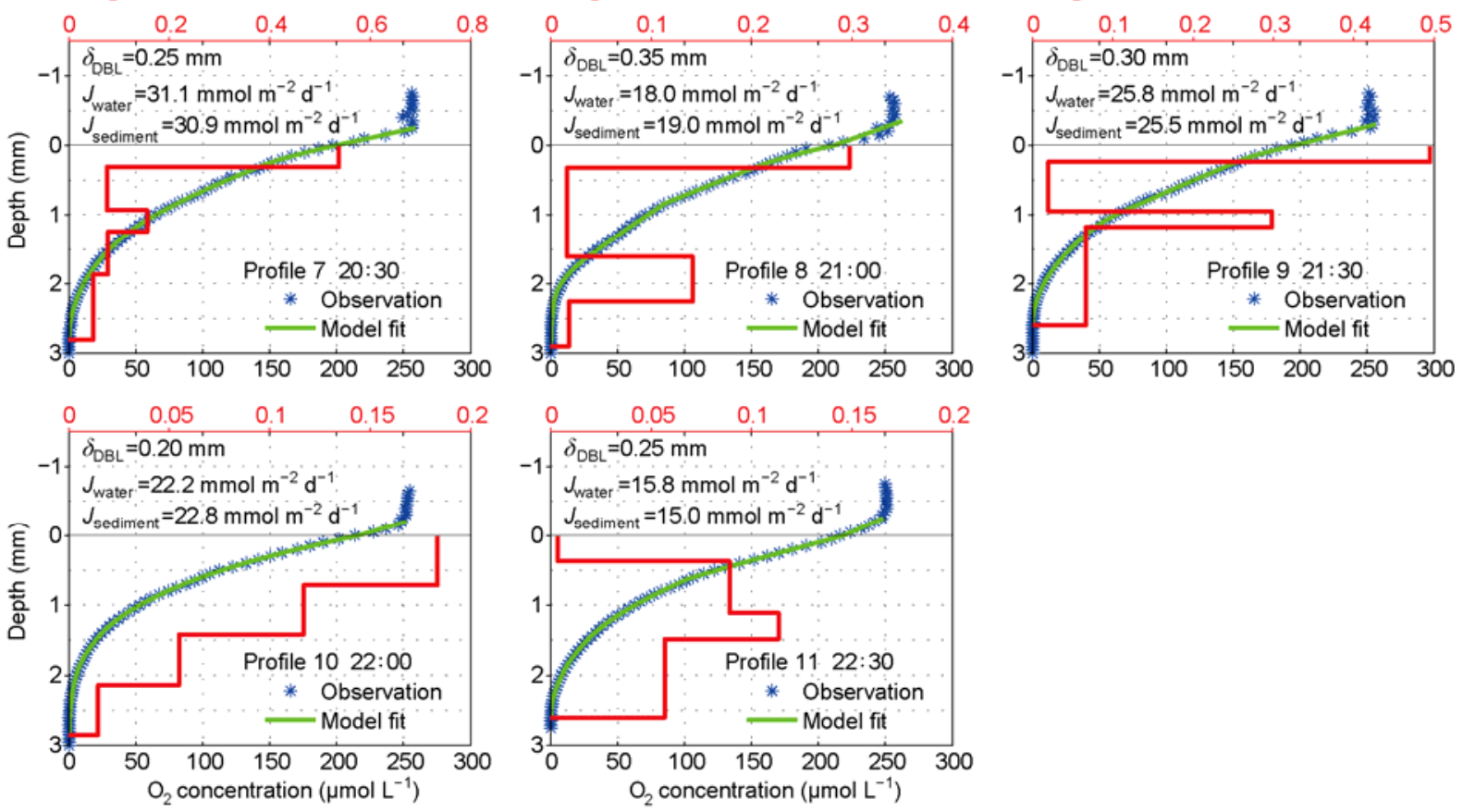

Figure 4 Profiles of dissolved oxygen concentration (blue star represents observations, green line model results, and red line the net rate of consumption per unit volume of sediment, calculated by the model).

net rate of oxygen consumption, to $0.1 \mathrm{nmol} \mathrm{cm}^{-3} \mathrm{~s}^{-1}$.

Figure 5 shows that oxygen consumption in the sediment oxic zone is not distributed evenly. The $25 \%$ of the upper oxic volume in the sediment that hosted the highest activity accounts for $60.5 \pm 13.8 \%$ of the integrated $\mathrm{O}_{2}$ consumption rate, while the $25 \%$ of the deeper oxic volume with the lowest activity is only responsible for $5.1 \pm 1.8 \%$ of this consumption (the remaining $75 \%$ of the upper oxic volume). This to some extent reflects that deeper oxic layers host a relatively low $\mathrm{O}_{2}$ consumption rate. On average, compartments in the depth ranges $1.0-2.0 \mathrm{~mm}$ and $2.0-3.0 \mathrm{~mm}$ are responsible for $15.0 \%$ and $2.0 \%$ of the total $\mathrm{O}_{2}$ consumption rate, whereas the very surface $(0.0-1.0 \mathrm{~mm})$ accounts for $41.0 \%$ of the $\mathrm{O}_{2}$ turnover. 


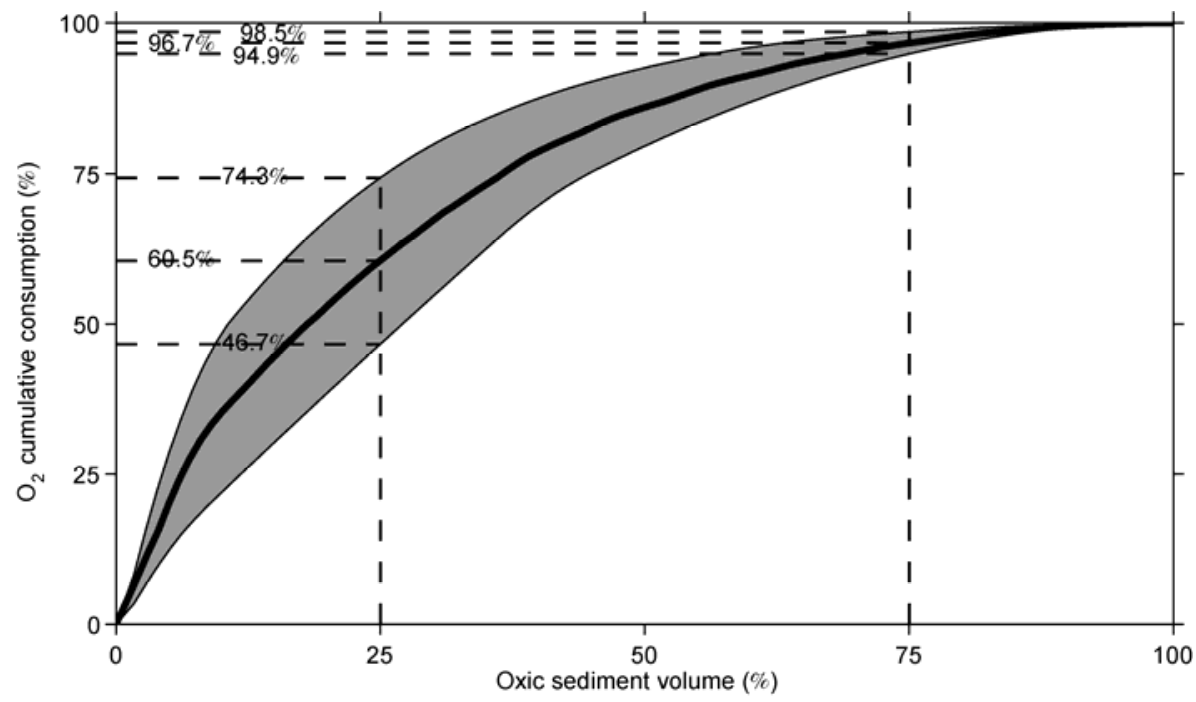

Figure 5 Cumulative contribution (gray region) of ranked sediment volumes to total $\mathrm{O}_{2}$ consumption for 11 measured oxygen profiles (black line in gray region represents the average value).

\subsection{DBL thickness and diffusion flux in response to dynamic forcing in $\mathrm{BBL}$}

Figure 6(a)-(d) shows time series of dynamic forcing in the BBL. The turbulent energy dissipation rate, friction velocity and turbulent energy are well correlated. Nevertheless, the relationship between the turbulent energy dissipation rate and mean velocity is not strong. This indicates that the turbulence is caused not only by shear of the mean velocity, but also probably by surface waves, local topography, sediment transport and buoyant flux [23-25]. Estimating the production of turbulence is limited by the data, and thus will not be discussed further.

A direct positive correlation was found between concentration in the BBL and mean velocity magnitude $U$ (Figure 7(a)-(c)). As flow speed increases, BBL oxygen concentration increases, and vice versa. Because the sediment over an intertidal mudflat is exposed to the air before measurement, pore water and corresponding oxygen contents are low. Gaseous oxygen is dissolved in the water when the tide rises and therefore sediment oxygen concentration increases considerably in the first four profiles (Figure 7(a)), from 45.5 to $102.9 \mu \mathrm{mol} \mathrm{L}{ }^{-1}$ at $0.5 \mathrm{~mm}$ below the SWI. The variation of penetration depth $z_{\max }$ is also influenced by the above process. Dissolved oxygen is continuously transported to sediment by molecular diffusion in the DBL, and the penetration depth therefore increases. Although the penetration depth in profiles 1-4 (Figure 7(a)) rapidly increases from 1.75 to $2.20 \mathrm{~mm}$, the overall average is only $1.93 \mathrm{~mm}$. As time progresses, the mean penetration depth of profiles 5-10 (Figure 7(b),(c)) jumps to $2.89 \mathrm{~mm}$. The tide level is near the oxygen probe and the molecular diffusion cannot extend through the last profile (Figure 7(c)), so the penetration depth declines to $2.65 \mathrm{~mm}$.

Figure 6(a) and (e) shows that the current mean velocity is inversely proportional to DBL thickness. The current mean velocity of profile $2(17: 41)$ peaks at $12.6 \mathrm{~cm} \mathrm{~s}^{-1}$, and the DBL thickness correspondingly falls to $0.10 \mathrm{~mm}$. When the mean velocity of profile $8(21: 00)$ minimizes at 1.1 $\mathrm{cm} \mathrm{s}^{-1}$, the corresponding DBL thickness rises to $0.35 \mathrm{~mm}$. Lorke et al. [18] found that DBL thickness increased following a decrease of turbulent dissipation. They documented that for highly energetic systems such as estuaries and tidal channels, flow speed drives the DBL thickness. However, in less energetic systems such as lakes and reservoirs, it was instead BBL turbulence that forced DBL thickness. Our results are consistent with this viewpoint. Because intertidal mudflats are high-energy systems (the turbulent dissipation order of magnitude is as high as $10^{-6} \mathrm{~W} \mathrm{~kg}^{-1}$ ), it is the flow speed rather than turbulent dissipation that determines DBL thickness. In our opinion, both flow speed and turbulence can influence DBL thickness, through suppressing this thickness and determining the smallest length scales of concentration fluctuations, respectively. The minimum of DBL thicknesses controlled by the two factors is the eventual thickness.

Over an intertidal mudflat where DBL thickness is controlled by current mean velocity, Figure 6(a) and (e) shows that DBL thickness increases with decreasing mean flow speed. Furthermore, proper parameterization of the mass transfer coefficient $\beta\left(\beta=D / \delta_{\mathrm{DBL}}\right)$ as a function of mean flow speed $U$ is also required for water quality modeling. From dimensional analysis ( $\mathrm{Pi}$ Theorem), the relation between DBL thickness $\delta_{\mathrm{DBL}}$, current mean velocity $U$, and molecular diffusion coefficient $D$ is $\delta_{\mathrm{DBL}}=a D U^{-1}+b$, where $a$ and $b$ are parameters. We do a polynomial fit and obtain $\delta_{\mathrm{DBL}}=1686.1 D U^{-1}+0.1$, where the unit of the molecular diffusion coefficient $D$ is $\mathrm{mm}^{2} \mathrm{~s}^{-1}$, that of current mean velocity is $\mathrm{mm} \mathrm{s}^{-1}$, and that of DBL thickness is $\mathrm{mm}$. The correlation coefficient $\left(R^{2}\right)$ of fitted and measured values is 0.90 


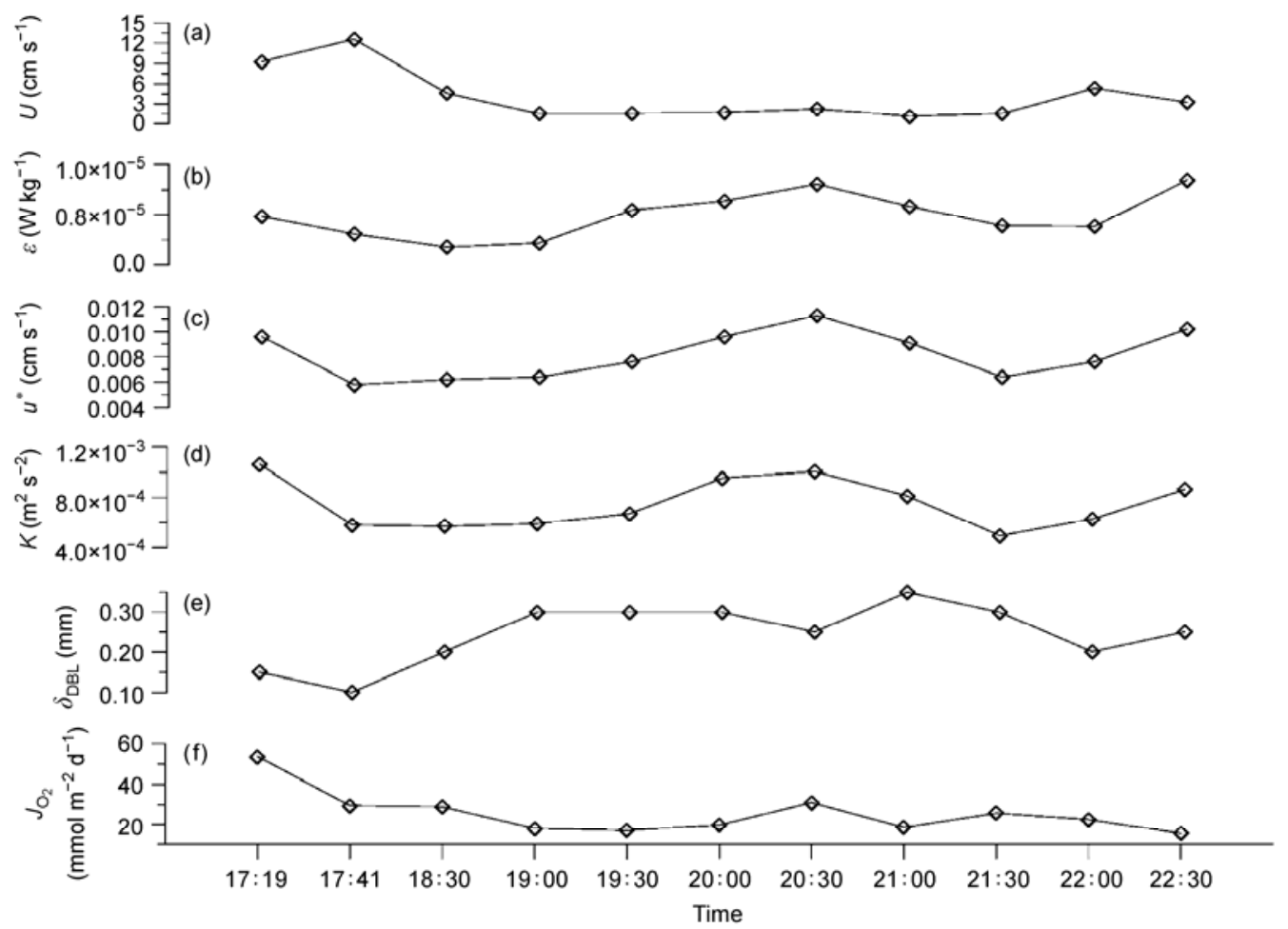

Figure 6 Time series of (a) mean velocity magnitude $U$, (b) turbulent energy dissipation rate $\varepsilon$, (c) friction velocity $u^{*}$, (d) turbulent energy $K$, (e) DBL thickness $\delta_{\mathrm{DBL}}$, (f) diffusion flux $J_{\mathrm{O}_{2}}$ into sediment.

and standard deviation of the differences between fitted and measured values is 0.02 , indicating that the formula predicts DBL thickness well (Figure 8). This formula was not applied to all situations because of limited observation data, but it was sufficient to discover that the variation of dynamics in the BBL significantly affects DBL thickness.

Time series of turbulent dissipation rate and diffusion flux are depicted in Figure 6(b) and (f). Except for profile 11, the variation of diffusion flux can be interpreted by two mechanisms, which are responses to the change of water overlying the sediment and to the turbulent intensity. The diffusion fluxes of profiles 1-4 are much greater, with an average up to $37.3 \mathrm{mmol} \mathrm{m}{ }^{-2} \mathrm{~d}^{-1}$. The sediment over an intertidal mudflat is exposed to the air before measurement. The pore water and corresponding oxygen contents are very low. When the tide floods, the concentration difference between sediment and water column (Figure 7(a)) causes the high flux. However, the diffusion fluxes of profiles 5-10 nearly follow the turbulent dissipation rate. In conjunction with Figure 6(b)-(d), we see that the diffusion flux is positively related to the turbulent dissipation rate, friction velocity and turbulent energy. As the turbulent dissipation rate rises, intense turbulent mixing probably improves the oxygen concentration in the BBL or diminishes DBL thickness to increase the diffusion flux, and vice versa. Although the turbulent dissipation rate of profile 11 is very high, the tide level fluctuates near the oxygen probe and therefore molec- ular diffusion cannot extend through the entire profile, so the flux decreases.

\section{Discussion and conclusion}

This research quantifies how dynamic forcing affects the variable DBL and diffusion flux at the SWI. Relevant discussion and significant conclusions follow.

(1) Use of the linear distributed zone in the oxygen profile, the slope discontinuity of the profile, and concentration variance can accurately give the DBL thickness. This thickness, which is between 0.10 and $0.35 \mathrm{~mm}$, varies with a factor of 3.5 over a tide period. An average DBL thickness of $0.25 \mathrm{~mm}$ reveals that it is a very thin layer above the SWI. The diffusion fluxes calculated from the water column and from the sediment remain the same, and their bias is less than $6 \%$. The dissolved oxygen diffusion flux into the sediment varies between 15.4 and $53.6 \mathrm{mmol} \mathrm{m}^{-2} \mathrm{~d}^{-1}$, with an average of $25.4 \mathrm{mmol} \mathrm{m}^{-2} \mathrm{~d}^{-1}$. As with the DBL thickness, the diffusion flux varies with a factor of 3.5 over one tide period. The DBL obtained from dissolved oxygen is also applicable to other solutes, such as $\mathrm{NO}_{3}^{-}$[26]. The traditional calculation of diffusion flux, which sets DBL thickness (or the concentration layer) order of magnitude at a centimeter, cannot achieve a correct result. We conclude that the DBL is critical to nutrient exchange flux at the SWI and nutrient reproduction within the sediment. 

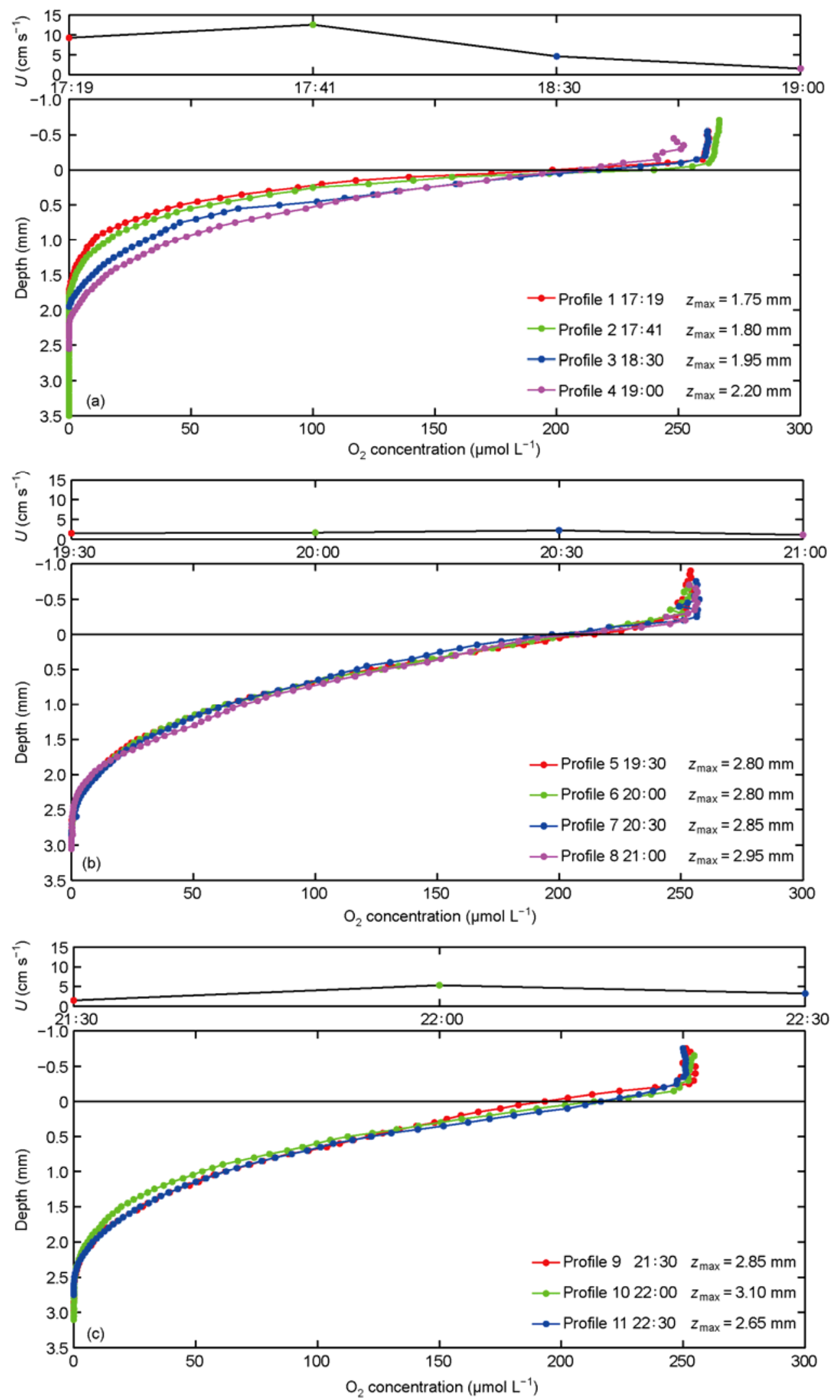

Figure 7 Relation between current mean velocity magnitude $U$ and oxygen profile, during flood tide (a), slack tide (b), ebb tide periods (c). 

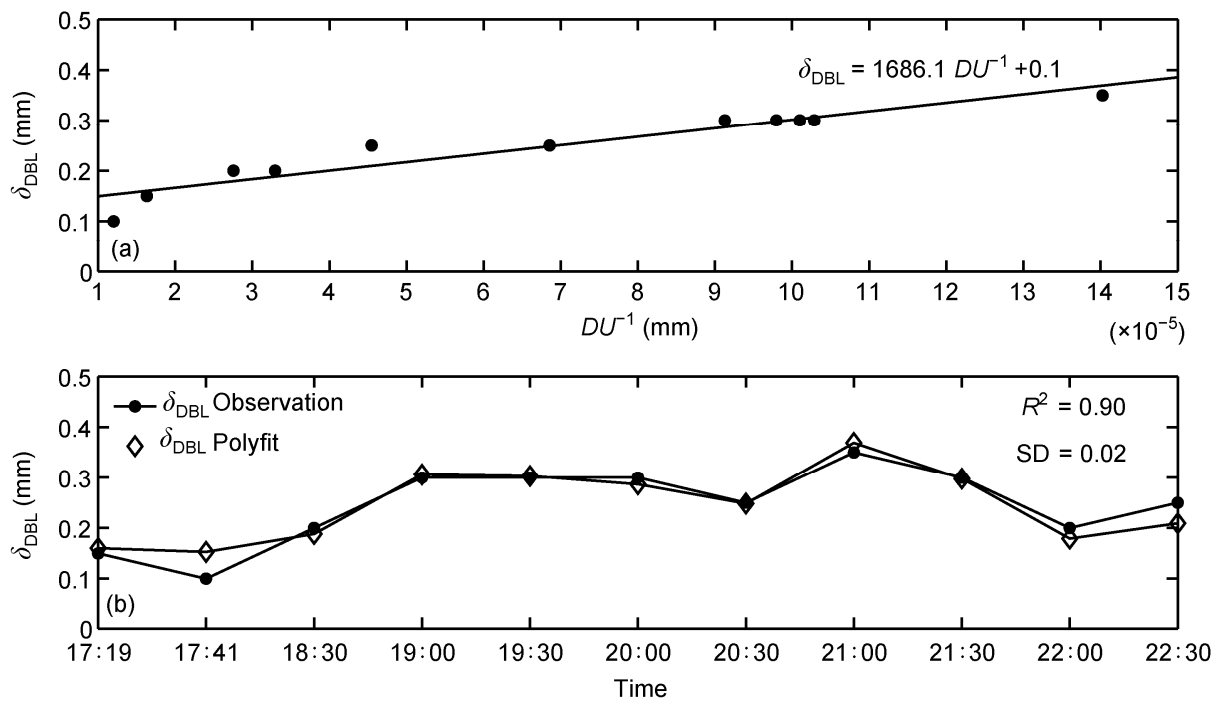

Figure 8 (a) Scatter diagram of $D U^{-1}$ in the BBL versus DBL thickness $\delta_{\mathrm{DBL}}$, with straight line showing the relationship fit; (b) time series of fitted (hollow diamond) and measured values (solid circle) of DBL thickness.

(2) Dynamic forcing in the BBL significantly affects DBL thickness and diffusion flux. Oxygen concentration is positively related to the current mean velocity in the BBL. Over an intertidal mudflat, DBL thickness is controlled by the current velocity $U$ in the $\mathrm{BBL}$, per $\delta_{\mathrm{DBL}}=1686.1$ $D U^{-1}+0.1$ ( $D$ is the molecular diffusion coefficient). That is, DBL thickness $\delta_{\mathrm{DBL}}$ increases with decreasing flow speed $U$. This formula supplements the Batchelor scale $\left(L_{\mathrm{B}}=\right.$ $\left.2 \pi\left(v D^{2} / \varepsilon\right)^{1 / 4}\right)$ [27], which is used to describe DBL thickness in systems where turbulence controls this thickness [18]. It is interesting that the variation of BBL thickness follows the speed $[23,24,28]$, contrary to the DBL finding. The variation of diffusion flux may be interpreted by two mechanisms, which are responses to the change of water overlying the sediment and the turbulent intensity.

Intertidal mudflats are influenced by the rise and fall of periodic tides. Dynamic mechanisms of variation in DBL thickness and diffusion flux are different from those in the open ocean. Future in situ measurements will be made in such ocean areas.

This work was supported by the National Basic Research Program of China (2011CB403606) and the National Natural Science Foundation of China (40830854 and 40806001).

1 Jørgensen B B, Revsbech N P. Diffusive boundary layers and the oxygen uptake of sediments and detritus. Limnol Oceanogr, 1985, 30: $111-122$

2 Gundersen J K, Jørgensen B B. Microstructure of diffusive boundary layers and the oxygen uptake of the sea floor. Nature, 1990, 345: 604-607

3 Wang Y, Gao S, Jia J. Flow structure in the marine boundary layer and bedload transport: A review (in Chinese). Mar Geol Quatern Geol, 2000, 3: 101-106

4 Higashino M, Stefan H G, Gantzer C J. Periodic diffusional mass transfer near sediment/water interface: Theory. J Environ Eng, 2003, 129: 447-455
5 Higashino M, Gantzer C J, Stefan H G. Unsteady diffusional mass transfer at the sediment/water interface: Theory and significance for SOD measurement. Water Res, 2004, 38: 1-12

6 Higashino M, O'Connor B L, Hondzo M, et al. Oxygen transfer from flowing water to microbes in an organic sediment bed. Hydrobiologia, 2008, 614: 219-231

7 Berg P, Glud R N, Hume A, et al. Eddy correlation measurements of oxygen uptake in deep ocean sediments. Limnol Oceanogr-Meth, 2009, 7: 576-584

8 Bryant L D, Lorrai C, McGinnis D F, et al. Variable sediment oxygen uptake in response to dynamic forcing. Limnol Oceanogr, 2010, 55: 950-964

9 Zhang Z, Cui G, Xu C. Theory and Modeling of Turbulence (in Chinese). Beijing: Tsinghua University Press, 2005. 98-102

10 Jørgensen B B, Des Marais D J. The diffusive boundary layer of sediments: Oxygen microgradients over a microbial mat. Limnol Oceanogr, 1990, 35: 1343-1355

11 Røy H, Hüttel M, Jørgensen B B. The role of small-scale sediment topography for oxygen fluxes across the diffusive boundary layer. Limnol Oceanogr, 2002, 47: 837-847

12 Sweerts J P R A, Louis V S T, Cappenberg T E. Oxygen concentration profiles and exchange in sediment cores with circulated overlying water. Freshwater Biol, 1989, 21: 401-409

13 Hondzo M. Dissolved oxygen transfer at the sediment-water interface in a turbulent flow. Water Resour Res, 1998, 34: 3525-3533

14 Steinberger N, Hondzo M. Diffusional mass transfer at sedimentwater interface. J Environ Eng, 1999, 125: 192-200

15 Reimers C E, Fischer K M, Merewether R, et al. Oxygen microprofiles measured in situ in deep ocean sediments. Nature, 1986, 320: $741-744$

16 Archer D, Emerson S, Smith C R. Direct measurement of the diffusive sublayer at the deep sea floor using oxygen microelectrodes. Nature, 1989, 340: 623-626

17 Glud R N, Stahl H, Berg P, et al. In situ microscale variation in distribution and consumption of $\mathrm{O}_{2}$ : A case study from a deep ocean margin sediment (Sagami Bay, Japan). Limnol Oceanogr, 2009, 54: 1-12

18 Lorke A, Müller B, Maerki M, et al. Breathing sediments: The control of diffusive transport across the sediment-water interface by periodic boundary-layer turbulence. Limnol Oceanogr, 2003, 48: 20772085

19 Liu Z, Wei H. Estimation to the turbulent kinetic energy dissipation rate and bottom shear stress in the tidal bottom boundary layer of the Yellow Sea. Prog Nat Sci, 2007, 17: 289-297 
20 Røy H, Huettel M, Jørgensen B B. Transmission of oxygen concentration fluctuations through the diffusive boundary layer overlying aquatic sediments. Limnol Oceanogr, 2004, 49: 686-692

21 Berg P, Risgaard-Petersen N, Rysgaard S. Interpretation of measured concentration profiles in sediment pore water. Limnol Oceanogr, 1998, 43: 1500-1510

22 Ramsing N, Gundersen J. Seawater and gases-Tabulated physical parameters of interest to people working with microsensors in marine systems. Version 2.0. Unisense Internal Report. 1994

$23 \mathrm{Liu} \mathrm{H}, \mathrm{Wu} \mathrm{C}, \mathrm{Xu} \mathrm{W}$, et al. Contrasts between estuarine and river systems in near-bed turbulent flows in the Zhujiang River (Pearl River) Estuary, China. Estuar Coast Shelf S, 2009, 83: 591-601

24 Wu J, Liu H, Ren J, et al. Cyclonic spirals in tidally accelerating bottom boundary layers in the Zhujiang River (Pearl River) Estuary. J
Phys Oceanogr, 2011, 41: 1209-1226

25 Wang Y, Gao S, Jia J. High-resolution data collection for analysis of sediment dynamic processes associated with combined current-wave action over intertidal flats. Chin Sci Bull, 2006, 51: 866-877

26 Lorenzen J, Larsen L H, Kjær T, et al. Biosensor determination of the microscale distribution of nitrate, nitrate assimilation, nitrification and denitrification in a diatom-inhabited freshwater sediment. Appl Environ Microbiol, 1998, 64: 3264-3269

27 Hearn C J, Robson J. Modelling a bottom diurnal boundary layer and its control of massive alga blooms in an estuary. Appl Math Mod, 2000, 24: 843-859

28 Lozovatsky I D, Liu Z, Wei H, et al. Tides and mixing in the northwestern East China Sea. Part I: Rotating and reversing flows. Cont Shelf Res, 2008, 28: 318-337

Open Access This article is distributed under the terms of the Creative Commons Attribution License which permits any use, distribution, and reproduction in any medium, provided the original author(s) and source are credited. 